\title{
Insulin may have a role to play in protecting beta cells from deterioration in diabetes. Reply to Del Parigi A [letter]
}

\author{
S. Andrikopoulos • J. Proietto
}

Received: 26 March 2008 / Accepted: 4 April 2008 / Published online: 29 April 2008

(C) Springer-Verlag 2008

To the Editor: We thank Dr Del Parigi [1] for reminding us of the protective effect of insulin therapy on beta cell function. This is more evidence that we could have quoted in our recent 'For Debate' article [2] proposing that resting the beta cell is protective, and its corollary, that overstimulation is detrimental.

Del Parigi supports his argument by referring to two studies in which short-term insulin therapy of newly diagnosed individuals with type 2 diabetes resulted in improved glycaemic control at 12 and 24 months posttreatment $[3,4]$. He concludes by suggesting that insulin may have 'a formidable role not only in long-standing and overly compromised patients with type 2 diabetes, but potentially also in newly diagnosed cases as a powerful means of achieving remission or a delay in the progression of the disease'.

While we agree that insulin therapy would have a protective effect on beta cells, we do not agree that insulin should be an early treatment for type 2 diabetes. Insulin therapy would be expected to result in increased weight [5] and blood pressure [6], and would expose the patient to the risk of hypoglycaemia. In fact, the UK Prospective Diabetes Study (UKPDS) showed that newly diagnosed patients with type 2 diabetes who were treated with insulin had increased weight gain and hypoglycaemic events, while glycaemic control $\left(\mathrm{HbA}_{1 \mathrm{c}}\right.$ levels) was similar to that achieved in patients treated with sulfonylurea or metformin [7]. There are other medications that lower blood glucose

\footnotetext{
S. Andrikopoulos $(\triangle) \cdot J$. Proietto

The University of Melbourne Department of Medicine (AH/NH),

Heidelberg Repatriation Hospital,

Building 24, 300 Waterdale Road, Heidelberg Heights,

Melbourne, VIC 3081, Australia

e-mail: sof@unimelb.edu.au
}

without stimulating the beta cell, including metformin, the glitazones (pioglitazone and rosiglitazone), acarbose and orlistat. In addition, agents that increase glucagon-like peptide 1 action and stimulate insulin secretion in the presence of hyperglycaemia, such as exenatide and the dipeptidyl-peptidase IV inhibitors (citagliptin and vildagliptin), also have independent beta cell protective effects [8], mitigating any detrimental effects of their stimulatory action.

It is time to rethink the order in which we use medications after diet and exercise no longer control the hyperglycaemia of type 2 diabetes, but we do not believe that insulin should be considered as an early therapy.

Duality of interest The authors declare that there is no duality of interest associated with this manuscript.

\section{References}

1. Del Parigi A (2008) Insulin may have a role to play in protecting beta cells from deterioration in diabetes. Diabetologia DOI 10.1007/ s00125-008-1010-3

2. Aston-Mourney K, Proietto J, Morahan G, Andrikopoulos S (2008) Too much of a good thing: why it is bad to stimulate the beta cell to secrete insulin. Diabetologia 51:540-545

3. Ryan EA, Imes S, Wallace C (2004) Short-term intensive insulin therapy in newly diagnosed type 2 diabetes. Diabetes Care 27: $1028-1032$

4. Li Y, Xu W, Liao Z et al (2004) Induction of long-term glycemic control in newly diagnosed type 2 diabetic patients is associated with improvement of beta-cell function. Diabetes Care 27:25972602

5. Palmer AJ, Roze S, Valentine WJ et al (2004) Deleterious effects of increased body weight associated with intensive insulin therapy for type 1 diabetes: increased blood pressure and worsened lipid profile partially negate improvements in life expectancy. Curr Med Res Opin 20(Supply 1):S67-S73 
6. Genev NM, Lau IT, Willey KA et al (1998) Does insulin therapy have a hypertensive effect in type 2 diabetes? J Cardiovasc Pharmacol 32:39-41

7. United Kingdom Prospective Diabetes Study Group (1998) United Kingdom Prospective Diabetes Study 24: a 6-year, randomized, controlled trial comparing sulfonylurea, insulin, and metformin therapy in patients with newly diagnosed type 2 diabetes that could not be controlled with diet therapy. Ann Intern Med 128:165-175

8. Xu G, Stoffers DA, Habener JF, Bonner-Weir S (1999) Exendin-4 stimulates both beta-cell replication and neogenesis, resulting in increased beta-cell mass and improved glucose tolerance in diabetic rats. Diabetes 48:2270-2276 